\title{
Fractal Characteristics of Rock Fracture Surface under Triaxial Compression after High Temperature
}

\author{
X. L. Xu ${ }^{1,2}$ and Z. Z. Zhang ${ }^{2}$ \\ ${ }^{1}$ School of Architecture and Civil Engineering, Nantong University, Nantong 226019, China \\ ${ }^{2}$ State Key Laboratory for Geomechanics and Deep Underground Engineering, School of Mechanics and Civil Engineering, \\ China University of Mining and Technology, Xuzhou 221116, China
}

Correspondence should be addressed to X. L. Xu; xuxiaoli@ntu.edu.cn

Received 15 June 2016; Accepted 8 September 2016

Academic Editor: Mikhael Bechelany

Copyright ( 92016 X. L. Xu and Z. Z. Zhang. This is an open access article distributed under the Creative Commons Attribution License, which permits unrestricted use, distribution, and reproduction in any medium, provided the original work is properly cited.

Scanning Electron Microscopy (SEM) test on 30 pieces of fractured granite has been researched by using S250MK III SEM under triaxial compression of different temperature $\left(25 \sim 1000^{\circ} \mathrm{C}\right)$ and confining pressure $(0 \sim 40 \mathrm{MPa})$. Research results show that $(1)$ the change of fractal dimension (FD) of rock fracture with temperature is closely related to confining pressure, which can be divided into two categories. In the first category, when confining pressure is in $0 \sim 30 \mathrm{MPa}$, FD fits cubic polynomial fitting curve with temperature, reaching the maximum at $600^{\circ} \mathrm{C}$. In the second category, when confining pressure is in $30 \sim 40 \mathrm{MPa}$, FD has volatility with temperature. (2) The FD of rock fracture varies with confining pressure and is also closely related to the temperature, which can be divided into three categories. In the first category, FD has volatility with confining pressure at $25^{\circ} \mathrm{C}, 400^{\circ} \mathrm{C}$, and $800^{\circ} \mathrm{C}$. In the second category, it increases exponentially at $200^{\circ} \mathrm{C}$ and $1000^{\circ} \mathrm{C}$. In the third category, it decreases exponentially at $600^{\circ} \mathrm{C}$. (3) It is found that $600^{\circ} \mathrm{C}$ is the critical temperature and $30 \mathrm{MPa}$ is the critical confining pressure of granite. The rock transfers from brittle to plastic phase transition when temperature exceeds $600^{\circ} \mathrm{C}$ and confining pressure exceeds $30 \mathrm{MPa}$.

\section{Introduction}

In 1982, French mathematician Mandelbrot [1] created the fractal geometry theory, which provided a new method for describing irregularities of distribution of nature. Xie [2, 3] first introduced fractal theory into the study of rock mechanics and opened a new way for the research of rock mechanics. After that, domestic scholars began to study fractal characteristics of rock fracture [4-7]. Peng et al. [8, 9] discussed the method of calculating FD of rock using boxcounting dimension according to the characteristics of twodimensional digital image. At the same time, relationship between porosity and FD was discussed by combining fractal theory with rock slice images obtained by CT scanning. Zuo et al. [10] developed analysis program of FD and lacunarity indices of rock SEM image and discussed the influence of magnification ratio and threshold size of the image on results.

In the aspect of studying the variation of FD of rock fracture with the change of confining pressure, $\mathrm{Ni}$ et al.
[11] researched the fractal on fracture surface of granite under different confining pressures. The study showed that, with the increase of confining pressure, FD increased along the direction of failure shear and was basically unchanged perpendicular to the direction. Chen et al. [12] defined the FD based on rock damage in order to describe the evolution of specimen under various loading conditions. The results showed that FD and damage variable increased gradually with the increase of load, and the initial damage of rock was delayed with the increase of confining pressure. Huang et al. [13] researched the distribution law of rock fragmentation and its correlation with energy dissipation and release combined with fractal theory and energy principle, based on triaxial high stress and unloading confining pressure tests of marble. Yang et al. [14] investigated triaxial compression test and CT scanning test under various confining pressure of tight sandstone; it was found that FD of crack showed exponential decline with the increase of confining pressure. 
In the aspect of FD of rock fracture with temperature, $\mathrm{Xu}$ et al. [15] systematically researched macro mechanical properties and micro pore structure characteristics of granite under temperature effect; the study found that FD of rock pore distribution decreased with temperature. Cao et al. [16] showed that, in $20 \sim 60^{\circ} \mathrm{C}$, relative changes of FD of rock surface topography increased with the rise of temperature after the action of water and decreased in $60 \sim 80^{\circ} \mathrm{C}$; the relative $\mathrm{FD}$ and water interaction temperature showed a parabolic function. Su et al. [17] found FD increased with the rise of temperature and loading rate; the damage form of sandstone transformed gradually from mixed tensile and shear failure to a single oblique shear failure; the extent of the damage was more and more serious. Zhang et al. [18] conducted statistical analysis of rock fragments under uniaxial compression of various temperature effect; it showed that FD of limestone decreased with temperature, which was a proper characteristic statistic that reflected the degree of fragmentation of limestone after high temperature. Zhang et al. $[19,20]$ calculated the correlation fractal dimensions (CFDs) of AE counts series at different stress level using Grassberger-Procaccia algorithm; as the heat temperature rises, the maximum $\mathrm{CFD}$ value and the corresponding stress level both increase from $25^{\circ} \mathrm{C}$ to $200^{\circ} \mathrm{C}$ and decrease from $200^{\circ} \mathrm{C}$ to $800^{\circ} \mathrm{C}$ and then increase again from $800^{\circ} \mathrm{C}$ to $1200^{\circ} \mathrm{C}$; the $\mathrm{CFD}$ value at the failure point shows polynomial decline with rising heat temperature.

Based on above research results, the FD of rock fracture mostly reflected the state of uniaxial compression under high temperature and triaxial compression at normal temperature; it is rarely reported in the condition of triaxial compression under high temperature. But in the development of geothermal resources, nuclear waste treatment, underground energy reserves, and other projects, rock is always in the coupling environment of temperature and confining pressure, so the study of deformation and failure mechanism of rock under different temperature and confining pressures has become a hot and frontier issue in the study of rock mechanics [2124]. The macroscopic mechanical properties of granite in the experimental temperature $\left(25 \sim 1000^{\circ} \mathrm{C}\right)$ and confining pressure $(0 \sim 40 \mathrm{MPa})$ had been studied in detail in the early stage [25]. Therefore, in this paper, the microscopic characteristics of rock after macro test are studied by Scanning Electron Microscope (SEM); the quantitative description of image obtained by SEM is analyzed by using box-counting method. Variation of FD of rock fracture with temperature and confining pressure is calculated in order to obtain some meaningful conclusions. The research results provide reference value for the study of macro fracture mechanism of rock under various temperature and pressure by using fractal theory.

\section{SEM Test}

2.1. Test Instrument. S250MKIII was used for SEM test, which is in the Analysis and Testing Center of China University of Mining and Technology. Its technical indicators are as follows: resolution is $60 \AA$, amplification factor is 200 thousand times, and accelerating voltage is $40 \mathrm{KV}$. AN10000 energy spectrometer and WDX-2A spectrometer are the main accessories. The application is quantitative micro analysis of solid material, surface structure, and element distribution.

2.2. Test Procedure. This test is mainly on the SEM analysis of granite under triaxial compression after high temperature. Firstly, cut the fracture of sample into appropriate size; clean the sample with acetone or alcohol to prevent illusion or with ultrasonic cleaning oscillator if necessary. Secondly, because rock minerals are nonconducting samples, charge accumulation can be generated under the action of electron beam; this will affect the trajectory of two electron motions of incident electron beam spot and sample emission; then the image quality will decline. Therefore, conductive layer should be sprayed before observation; usually using gold or silver or carbon film with the secondary electron emission coefficient is higher; the film thickness is controlled at about $20 \mu \mathrm{m}$. Finally, the sample is bonded to the sample holder with a conductive adhesive, and then put it into vacuum chamber to observe.

The test has six temperature points of 25 (normal temperature), $200,400,600,800$, and $1000^{\circ} \mathrm{C}$ and five confining pressures of 0 (uniaxial compression), 10, 20, 30, and $40 \mathrm{MPa}$; it consists of 30 samples; each rock sample scans 8-10 pieces of images.

\section{Fractal Theory}

In fractal theory, the common FD has capacity dimension, information dimension, correlation dimension, general dimension, self-similar dimension, and so on. FD of Cantor set, Koch curve, Sierpinski set, and Menger sponge can be obtained by using self-similar dimension, because they have strict self-similarity, which can be estimated according to the generating element and structural rules. Fractal in nature is statistical self-similarity and unable to determine the generation of a natural fractal; therefore, in the study of rock mechanics, the box-counting dimension is widely used by many researchers, mainly because the box-counting dimension can be a good description and characterization of crack morphology of irregular characteristics, and the mathematical calculation and estimation are relatively easy. In this paper, FD of rock fracture is calculated by boxcounting method. The box-counting dimension is calculated using cover method. Because the crack of rock has the characteristics of fractal distribution, it can be regarded as a fractal set of $F$; cover the cracks of rock fracture surface with a square lattice; the size of grid is changing. Given $\delta$ as the size of box, the total number $(N)$ of boxes covered with cracks can be counted. Assuming using the grid of $\delta_{k} \times \delta_{k}$ to cover the crack at the $k$ step, $N_{\delta_{k}}$ is the required number of boxes; then the formula of box-counting dimension is as follows [8]:

$$
D=\lim _{k \rightarrow \infty} \frac{\ln N_{\delta_{k}}(F)}{-\ln \delta_{k}},
$$

where $\delta_{k}$ is the length of side grid covered rock cracks and $N_{\delta_{k}}$ is the intersection grid number with intersection of fractal set of $F$. 
TABLE 1: Average value of fractal dimension of rock fracture under different temperature and confining pressure.

\begin{tabular}{lcccccc}
\hline \multirow{2}{*}{ Confining pressure MPa } & \multicolumn{6}{c}{ Temperature ${ }^{\circ} \mathrm{C}$} \\
& 25 & 200 & 400 & 600 & 800 & 1000 \\
\hline \multicolumn{6}{c}{ Fractal dimension } \\
0 & 1.905 & 1.894 & 1.965 & 1.973 & 1.954 & 1.772 \\
10 & 1.937 & 1.947 & 1.968 & 1.974 & 1.943 & 1.853 \\
20 & 1.915 & 1.957 & 1.955 & 1.974 & 1.949 & 1.940 \\
30 & 1.846 & 1.979 & 1.932 & 1.953 & 1.953 & 1.939 \\
40 & 1.935 & 1.976 & 1.975 & 1.915 & 1.941 & 1.946 \\
\hline
\end{tabular}

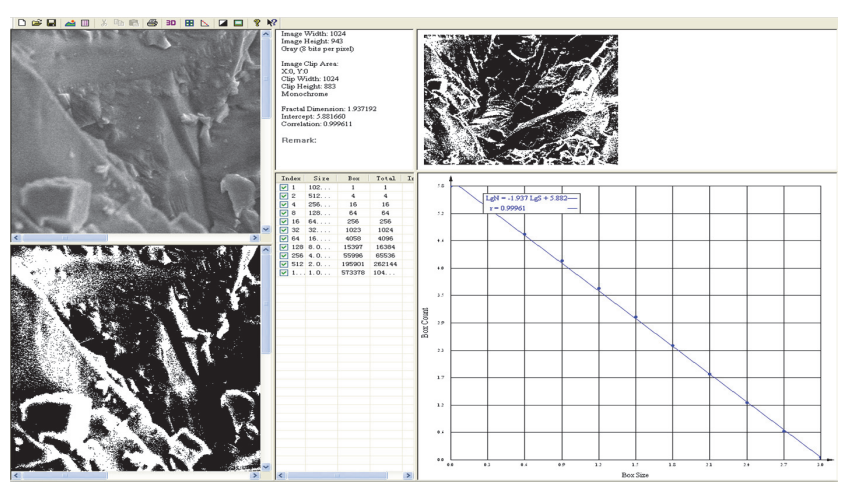

FIGURE 1: Calculation software of fractal dimension.

Because the fractal set of $F$ is composed of points, when $\delta$ reduces to a certain value of $|F|(|F|=\inf \{|X-Y|$ : $X, Y \in F\}), N_{\delta_{k}}$ will be a fixed value and no longer varies with the change of $k$. Therefore, in practical applications, the usual practice is to seek a series of $\delta_{k}$ and $N_{\delta_{k}}$; then the linear slope of the $\log \delta_{k}-\log N_{\delta_{k}}$ graph in the double logarithm coordinate is the FD.

Based on above basic theory, FD of rock fracture can be obtained by SEM images. Calculation step includes importing image, processing image, calculating area, covering number of statistics box, calculating box-counting dimension, and deriving calculation results. Figure 1 is an introduction of calculating FD using SEM images at the temperature of $25^{\circ} \mathrm{C}$ and confining pressure of $10 \mathrm{MPa}$.

\section{Test Results and Analysis}

4.1. SEM Image. FD of 8 pieces of SEM images for each sample is calculated by box-counting method; the average value is taken as the final value in each case. Select 30 images closest to the average FD in 200 pieces of SEM images, as shown in Figure 2.

4.2. Fractal Dimension Results. Through calculation, the average value of FD under various temperature and confining pressure is shown in Table 1.

4.3. Variation of Fractal Dimension of Rock Fracture with Temperature under Different Confining Pressure. According to the data in Table 1, FD with temperature under 0 (uniaxial compression), 10, 20, 30, and $40 \mathrm{MPa}$ is plotted, as shown in Figure 3.

The change of FD with temperature is discussed, respectively, under various confining pressure.

(a) The change of FD with temperature can be divided into two stages under $0 \mathrm{MPa}$ (uniaxial compression). In the first stage, $\mathrm{FD}$ of $25 \sim 600^{\circ} \mathrm{C}$ increases with the rising temperature, which is increased from 1.905 of $25^{\circ} \mathrm{C}$ to 1.973 of $600^{\circ} \mathrm{C}$, with an increase of $3.57 \%$; in the second stage, $\mathrm{FD}$ of $600 \sim 1000^{\circ} \mathrm{C}$ is rapidly decreased, which is decreased from 1.973 of $600^{\circ} \mathrm{C}$ to 1.775 of $1000^{\circ} \mathrm{C}$, with a decline of $10.19 \%$, reaching the maximum value at $600^{\circ} \mathrm{C}$. FD is in accordance with cubic polynomial fitting curve with the increase of temperature. Fitting formula is $D_{0 \mathrm{MPa}}=A_{1}+$ $B_{1} T+C_{1} T^{2}+D_{1} T^{3}$, fitting parameters are $A_{1}=$ $1.90844, B_{1}=-2.64352 \times 10^{-4}, C_{1}=1.44781 \times 10^{-6}$, and fitting correlation coefficient is $R^{2}=0.95411$.

(b) When confining pressure is $10 \mathrm{MPa}$, the variation of FD with temperature is the same as uniaxial compression. It is also in line with cubic polynomial fitting curve. Fitting formula is $D_{10 \mathrm{MPa}}=A_{2}+$ $B_{2} T+C_{2} T^{2}+D_{2} T^{3}$, fitting parameters are $A_{2}=$ 1.93677, $B_{2}=-7.96194 \times 10^{-6}, C_{2}=4.0472 \times 10^{-7}$, and $D_{2}=-4.80647 \times 10^{-10}$, and fitting correlation coefficient is $R^{2}=0.99984$.

(c) When confining pressure is $20 \mathrm{MPa}, \mathrm{FD}$ can also be divided into two stages as the temperature increases. The first stage, FD of $25 \sim 600^{\circ} \mathrm{C}$, rises from 1.937 of $25^{\circ} \mathrm{C}$ to 1.974 of $600^{\circ} \mathrm{C}$, with an increase of $1.91 \%$; the second stage, $\mathrm{FD}$ of $600 \sim 1000^{\circ} \mathrm{C}$ drops from 1.974 of $600^{\circ} \mathrm{C}$ to 1.853 of $1000^{\circ} \mathrm{C}$, with a decline of $6.13 \%$, reaching maximum value at $600^{\circ} \mathrm{C}$. Fitting formula is $D_{20 \mathrm{MPa}}=A_{3}+B_{3} T+C_{3} T^{2}+D_{3} T^{3}$, fitting parameters are $A_{3}=1.91006, B_{3}=2.75661 \times 10^{-4}, C_{3}=$ $-4.01132 \times 10^{-7}$, and $D_{3}=1.54725 \times 10^{-10}$, and correlation coefficient is $R^{2}=0.64702$; the correlation coefficient is not high.

(d) When confining pressure is $30 \mathrm{MPa}, \mathrm{FD}$ is fluctuating with temperature. The change of FD can still be divided into two stages except $200^{\circ} \mathrm{C}$. It increases from 1.846 of $25^{\circ} \mathrm{C}$ to 1.953 of $600^{\circ} \mathrm{C}$, with $5.79 \%$ increase, and drops from 1.953 of $600^{\circ} \mathrm{C}$ to 1.939 of $1000^{\circ} \mathrm{C}$, compared to $0 \sim 20 \mathrm{MPa}$ with a smaller decline, only $0.72 \%$. There is no better fitting relationship between FD and temperature. It can be seen that when confining pressure is $30 \mathrm{MPa}$, the influence of temperature on FD is reduced.

(e) When confining pressure is $40 \mathrm{MPa}, \mathrm{FD}$ has no better fitting curve with temperature. It is worth noting that it drops from 1.975 of $400^{\circ} \mathrm{C}$ to 1.915 of $600^{\circ} \mathrm{C}$ and then increased to 1.946 of $1000^{\circ} \mathrm{C}$, reaching the minimum at $600^{\circ} \mathrm{C}$. The change of FD in $400 \sim 1000^{\circ} \mathrm{C}$ is just opposite to the same range of temperature in 0 30 MPa, the increase of confining pressure weakens the influence of temperature on FD, and the confining pressure plays a key role in this case. 


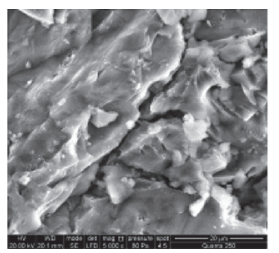

$25^{\circ} \mathrm{C}$

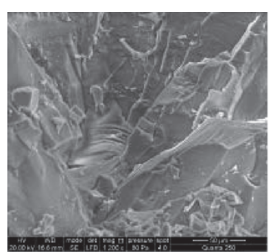

$25^{\circ} \mathrm{C}$

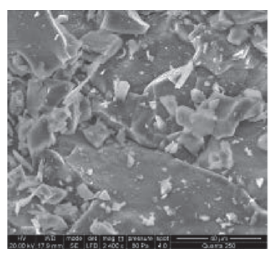

$25^{\circ} \mathrm{C}$

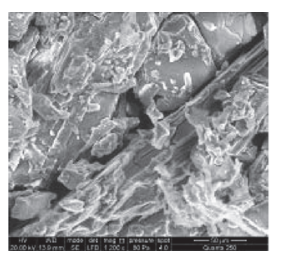

$25^{\circ} \mathrm{C}$

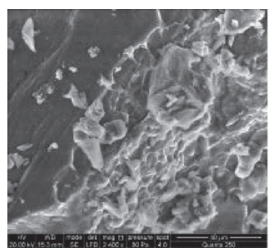

$25^{\circ} \mathrm{C}$

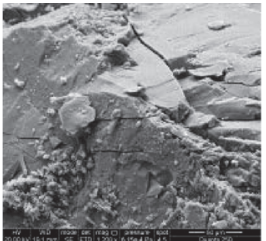

$200^{\circ} \mathrm{C}$

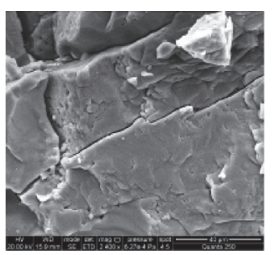

$200^{\circ} \mathrm{C}$

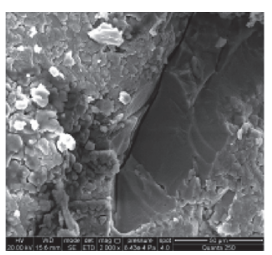

$200^{\circ} \mathrm{C}$

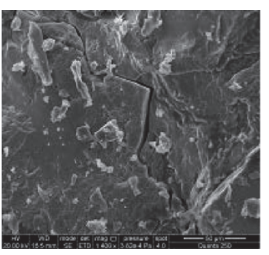

$200^{\circ} \mathrm{C}$

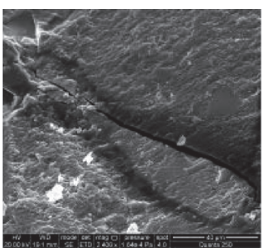

$200^{\circ} \mathrm{C}$

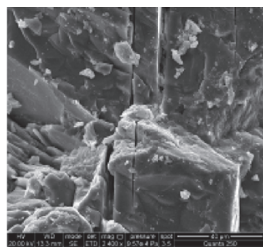

$400^{\circ} \mathrm{C}$

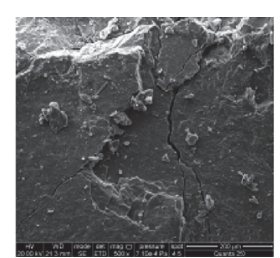

$600^{\circ} \mathrm{C}$

(a) $0 \mathrm{MPa}$ (uniaxial compression)

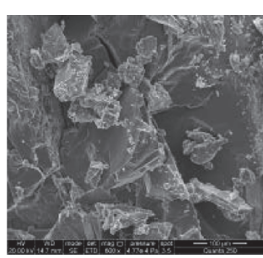

$400^{\circ} \mathrm{C}$

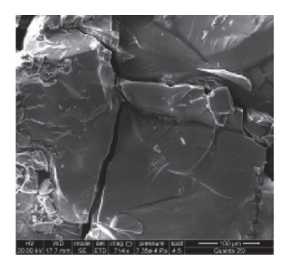

$600^{\circ} \mathrm{C}$

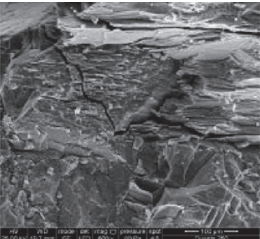

$800^{\circ} \mathrm{C}$

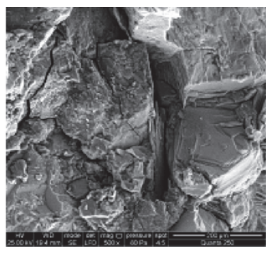

$800^{\circ} \mathrm{C}$

(b) $10 \mathrm{MPa}$

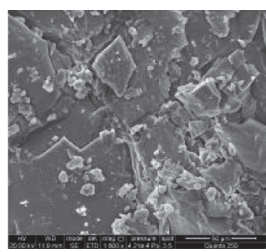

$400^{\circ} \mathrm{C}$

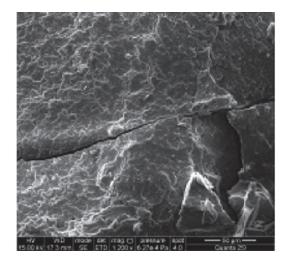

$600^{\circ} \mathrm{C}$

(c) $20 \mathrm{MPa}$

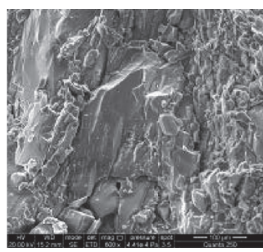

$400^{\circ} \mathrm{C}$

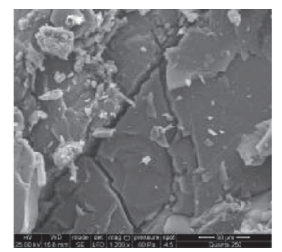

$600^{\circ} \mathrm{C}$

(d) $30 \mathrm{MPa}$

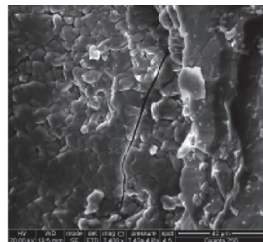

$400^{\circ} \mathrm{C}$

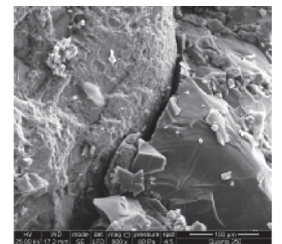

$600^{\circ} \mathrm{C}$

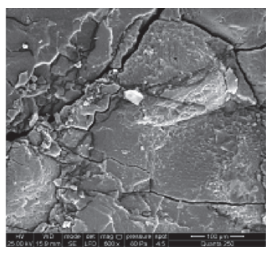

$800^{\circ} \mathrm{C}$

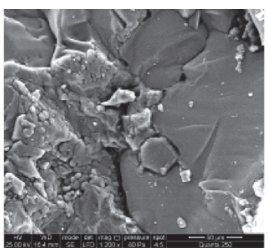

$800^{\circ} \mathrm{C}$

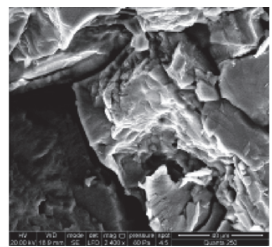

$800^{\circ} \mathrm{C}$

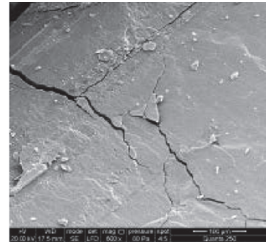

$1000^{\circ} \mathrm{C}$

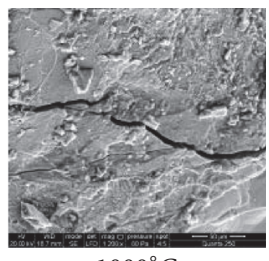

$1000^{\circ} \mathrm{C}$

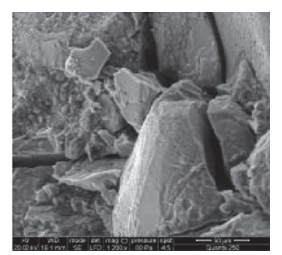

$1000^{\circ} \mathrm{C}$

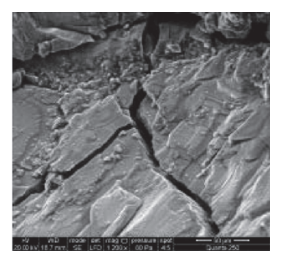

$1000^{\circ} \mathrm{C}$

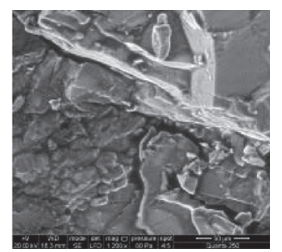

$1000^{\circ} \mathrm{C}$

(e) $40 \mathrm{MPa}$

FIGURE 2: SEM image of rock fracture under different temperature and confining pressure.

At the same time, FD of rock fracture under various confining pressures is plotted in Figure 4, so that the whole analysis can be carried out.

It can be educed that, in the test range of temperature (25 $\left.1000^{\circ} \mathrm{C}\right)$ and confining pressure $(0 \sim 40 \mathrm{MPa})$, the variation of FD of SEM images as temperature rises is closely related to confining pressure; it can be divided into two categories generally.

(1) In the first category, when confining pressure is in $0 \sim 30 \mathrm{MPa}$, the change of FD with temperature can be divided into two stages. FD first increases and then decreases with the rise of temperature, reaching maximum value at $600^{\circ} \mathrm{C}$ (except $30 \mathrm{MPa}$ ). It can be inferred that $600^{\circ} \mathrm{C}$ is a critical temperature. $\mathrm{FD}$ is in accordance with cubic polynomial fitting curve with temperature, but with the increase of confining pressure, the correlation coefficient of fitting curve decreases; there is no better fitting curve at $30 \mathrm{MPa}$.

(2) In the second category, when confining pressure is in $30 \sim 40 \mathrm{MPa}$, the change of $\mathrm{FD}$ of $400 \sim 1000^{\circ} \mathrm{C}$ is just contrary to the law of $0 \sim 30 \mathrm{MPa}$; the influence of confining pressure plays a key role on FD in this case. 


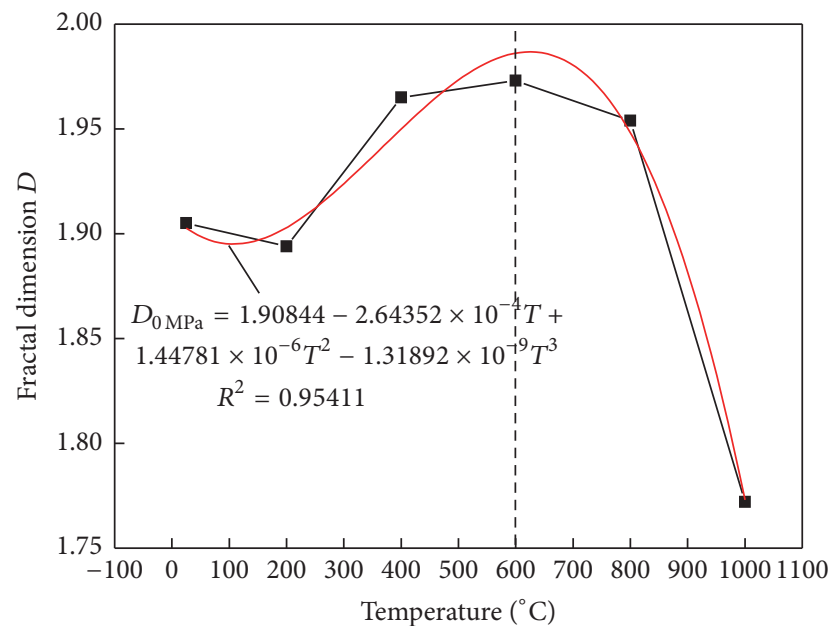

(a) $0 \mathrm{MPa}$ (uniaxial compression)

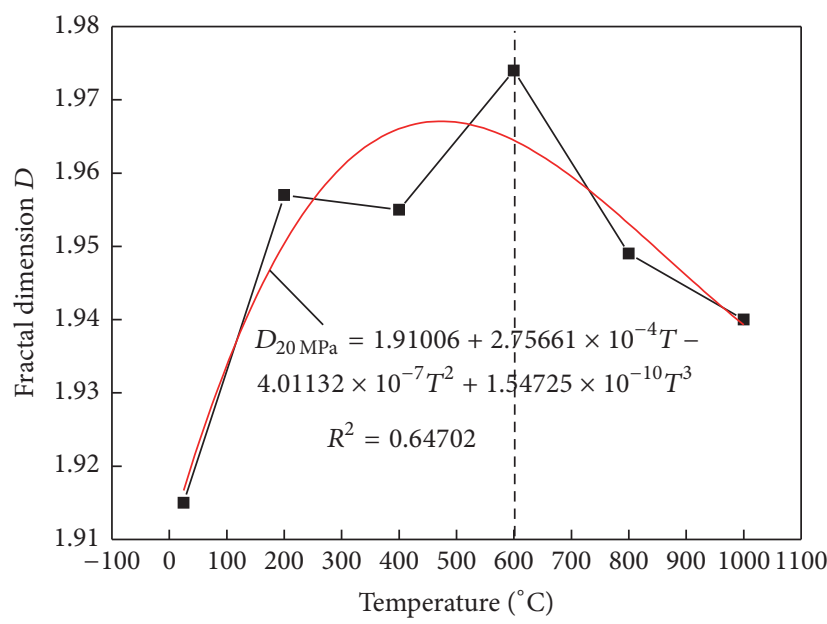

(c) $20 \mathrm{MPa}$

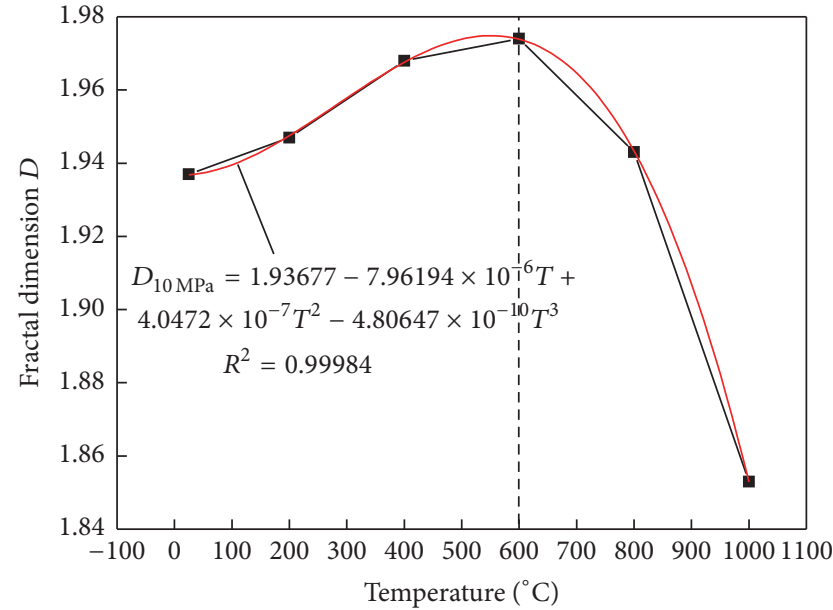

(b) $10 \mathrm{MPa}$

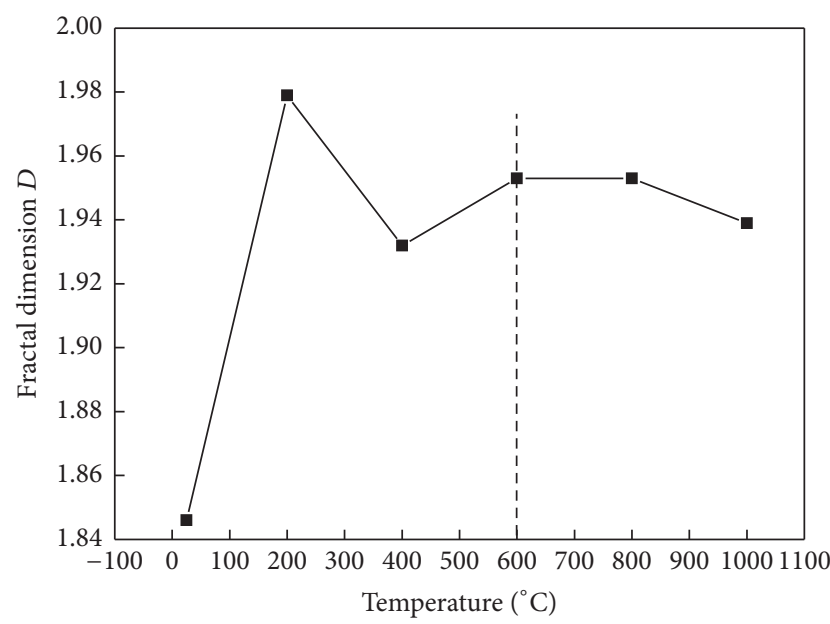

(d) $30 \mathrm{MPa}$

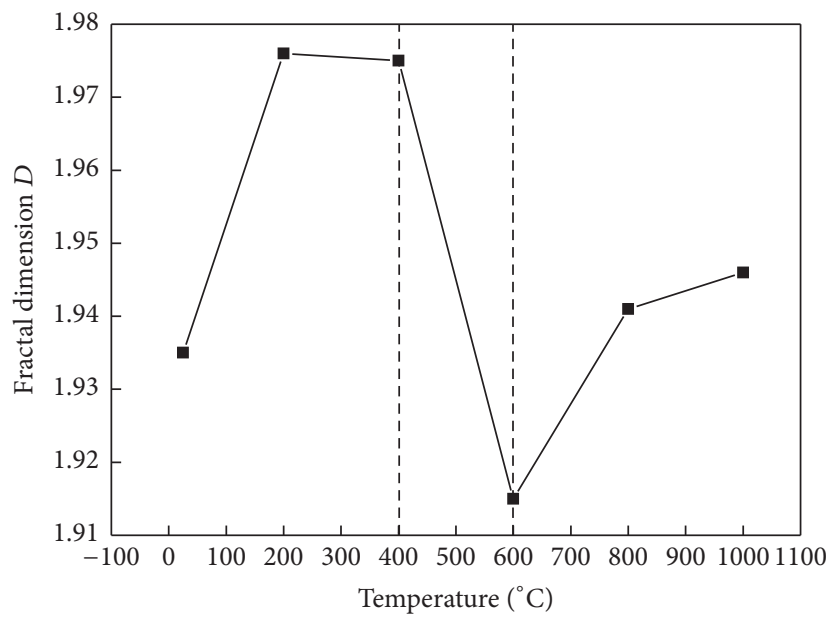

(e) $40 \mathrm{MPa}$

FIgURE 3: Relationship between fractal dimension and temperature. 


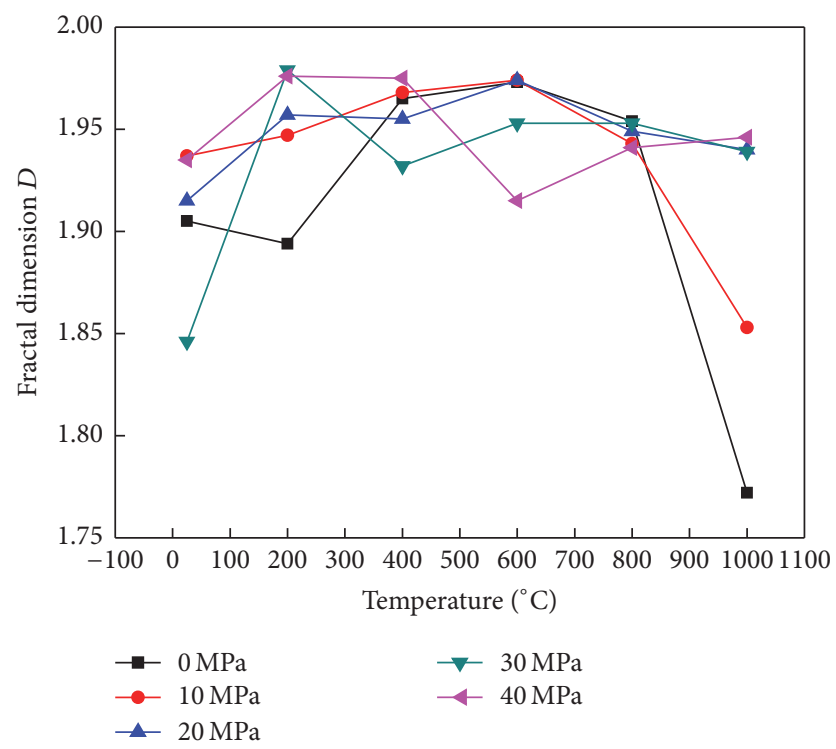

FIGURE 4: Relationship between fractal dimension and temperature under confining pressure at all levels.

4.4. Variation of Fractal Dimension of Rock Fracture with Confining Pressure under Different Temperature. According to the data in Table 1, curves of FD of rock fracture are drawn of 25 (normal temperature), $200,400,600,800$, and $1000^{\circ} \mathrm{C}$ under various confining pressure, as shown in Figure 5.

The change of FD of rock fracture with confining pressure is discussed, respectively, under different temperature.

(a) FD fluctuates with confining pressure at $25^{\circ} \mathrm{C}$; it can be divided into three stages. In the first stage, it increases from 1.905 of $0 \mathrm{MPa}$ to 1.937 of $10 \mathrm{MPa}$, with an increase of $1.68 \%$; in the second stage, it decreases from 1.937 of $10 \mathrm{MPa}$ to 1.846 of $30 \mathrm{MPa}$, with a decline of $4.69 \%$; since then, as the confining pressure increases to $40 \mathrm{MPa}$, it increases to 1.935 , with an increase of 4.82 .

(b) When temperature is $200^{\circ} \mathrm{C}, \mathrm{FD}$ increases from 1.894 of $0 \mathrm{MPa}$ to 1.979 of $30 \mathrm{MPa}$, with an increase of $4.49 \%$; then it decreases slightly, down to 1.976 of $40 \mathrm{MPa}$. At this temperature, the least square method is used to fit the test curve; the FD is better to satisfy exponential growth with the increase of confining pressure. Fitting formula is $D_{200}=A_{1} e^{-\sigma_{3} / t_{1}}+$ $B_{1}$, fitting parameters are $A_{1}=-0.08561, t_{1}=$ 11.85637, and $B_{1}=1.98021$, and fitting correlation coefficient is $R^{2}=0.9572$.

(c) When temperature is $400^{\circ} \mathrm{C}$, the variation of FD with confining pressure is consistent with $25^{\circ} \mathrm{C}$, which can also be divided into three stages. From 0 to $10 \mathrm{MPa}$, it increases from 1.965 to 1.968 , with an increase of $0.15 \%$; from 10 to $30 \mathrm{MPa}$, it decreases from 1.968 to 1.932 , with a decline of $1.83 \%$; thereafter, it increases to 1.975 of $40 \mathrm{MPa}$, with an increase of $2.23 \%$.

(d) When temperature is $600^{\circ} \mathrm{C}, \mathrm{FD}$ can be divided into two stages with the rise of confining pressure. In the first stage, there is no variation of FD from 0 to $20 \mathrm{MPa}$; in the second stage, it decreases from 1.974 of $20 \mathrm{MPa}$ to 1.915 of $40 \mathrm{MPa}$, with a decline of $2.99 \%$. FD decreases with exponential function with confining pressure, fitting formula is $D_{600}=A_{2} e^{-\sigma_{3} / t_{2}}+B_{2}$, fitting parameters are $A_{2}=-7.41887 \times 10^{-4}, t_{2}=$ -9.05242, and $B_{2}=1.97614$, and fitting correlation coefficient is $R^{2}=0.97335$; the fitting curve is just opposite to $200^{\circ} \mathrm{C}$.

(e) When temperature is $800^{\circ} \mathrm{C}, \mathrm{FD}$ can be divided into three stages with confining pressure, but the change trend is just opposite to $25^{\circ} \mathrm{C}$ and $400^{\circ} \mathrm{C}$. From 0 to $10 \mathrm{MPa}$, it decreases from 1.954 to 1.943 , with a decline of $0.56 \%$, and then increases to 1.953 of $30 \mathrm{MPa}$, with an increase of $0.52 \%$; thereafter, it is down to 1.941 of $40 \mathrm{MPa}$, with a decline of $0.61 \%$. As can be seen, FD changes with fluctuation of confining pressure at $800^{\circ} \mathrm{C}$; the overall change is smaller. It can be approximated that $\mathrm{FD}$ of $800^{\circ} \mathrm{C}$ is mainly controlled by temperature, and the confining pressure has no obvious effect on it.

(f) When temperature is $1000^{\circ} \mathrm{C}, \mathrm{FD}$ can be divided into two stages. From 0 to $20 \mathrm{MPa}$, it increases from 1.772 to 1.940 , with a decline of $9.48 \%$; it basically has no change from 20 to $40 \mathrm{MPa}$. FD increases with exponential curve with confining pressure, fitting formula is $D_{1000}=A_{3} e^{-\sigma_{3} / t_{3}}+B_{3}$, fitting parameters are $A_{3}=-0.19436, t_{3}=13.62916$, and $B_{3}=1.96286$, and fitting correlation coefficient is $R^{2}=0.93008$. The change tendency of FD of $1000^{\circ} \mathrm{C}$ with confining pressure is consistent with $200^{\circ} \mathrm{C}$, both in exponential function growth.

In order to carry on the whole analysis, draw the change of FD of rock fracture with confining pressure at all kinds of temperature in the same figure, as shown in Figure 6.

It can be seen that, in the test range of temperature (25 $\left.1000^{\circ} \mathrm{C}\right)$ and confining pressure $(0 \sim 40 \mathrm{MPa})$, the variation of FD of SEM images with confining pressure is closely related to temperature, which can be divided into the following three categories.

(1) In the first category, FD has volatility with the change of confining pressure at $25^{\circ} \mathrm{C}, 400^{\circ} \mathrm{C}$, and $800^{\circ} \mathrm{C}$; it can be divided into three stages.

(2) In the second category, FD increases exponentially with confining pressure at $200^{\circ} \mathrm{C}$ and $1000^{\circ} \mathrm{C}$. Fitting curve of $200^{\circ} \mathrm{C}$ is $D_{200}=-0.08561 e^{-\sigma_{3} / 11.85637}+$ 1.98021 ; fitting correlation coefficient is $R^{2}=$ 0.9572 ; fitting curve of $1000^{\circ} \mathrm{C}$ is $D_{1000}=$ $-0.19436 e^{-\sigma_{3} / 13.62916}+1.96286$; fitting correlation coefficient is $R^{2}=0.93008$.

(3) In the third category, FD decreases exponentially with confining pressure at $600^{\circ} \mathrm{C}$. Fitting curve is $D_{600}=$ $-7.41887 \times 10^{-4} e^{\sigma_{3} / 9.05242}+1.97614$; fitting correlation coefficient is $R^{2}=0.97335$. 


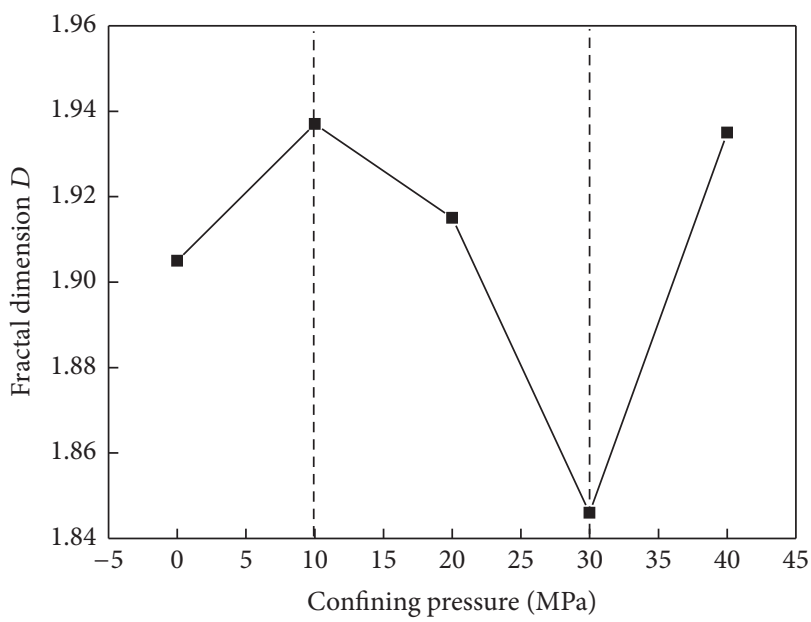

(a) $25^{\circ} \mathrm{C}$ (normal temperature)

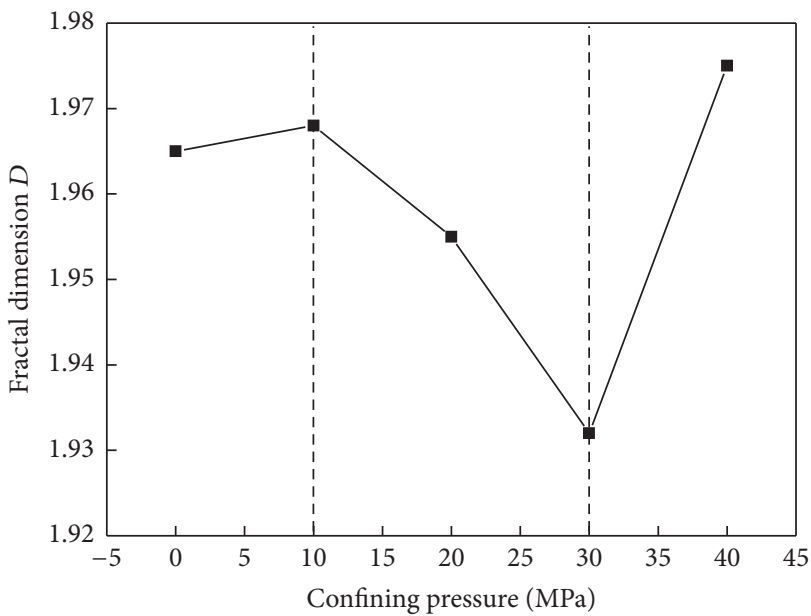

(c) $400^{\circ} \mathrm{C}$

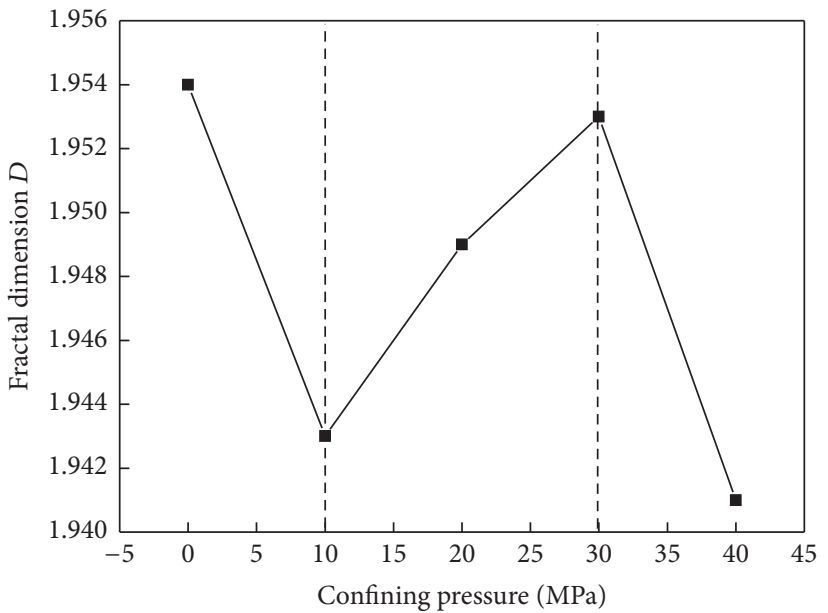

(e) $800^{\circ} \mathrm{C}$

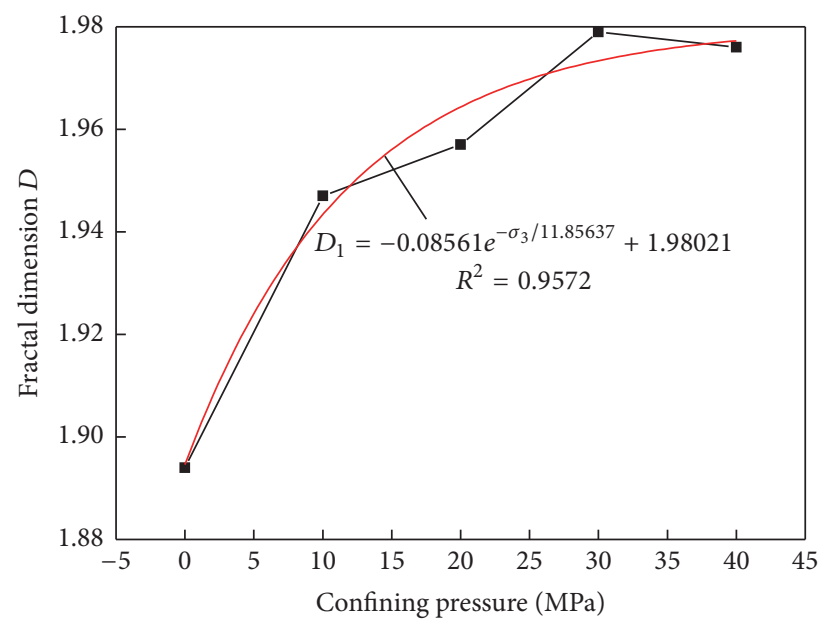

(b) $200^{\circ} \mathrm{C}$

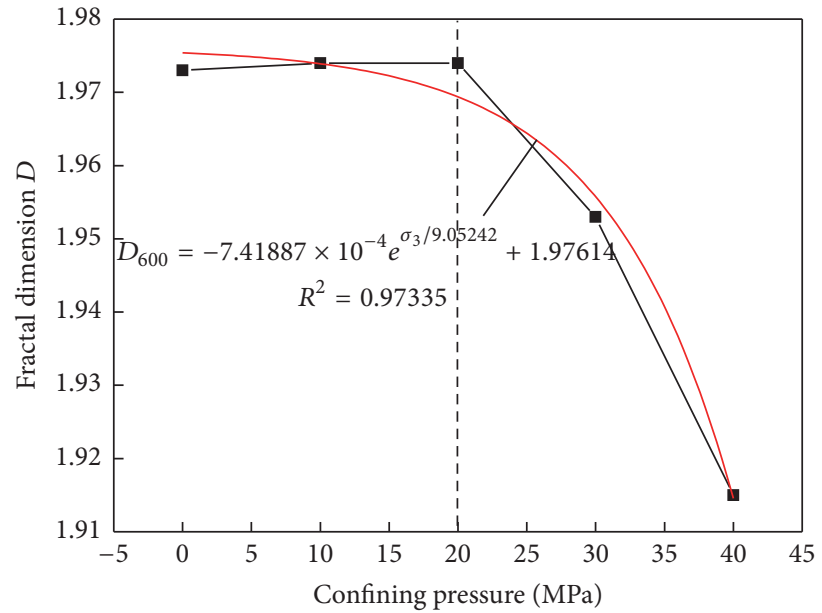

(d) $600^{\circ} \mathrm{C}$

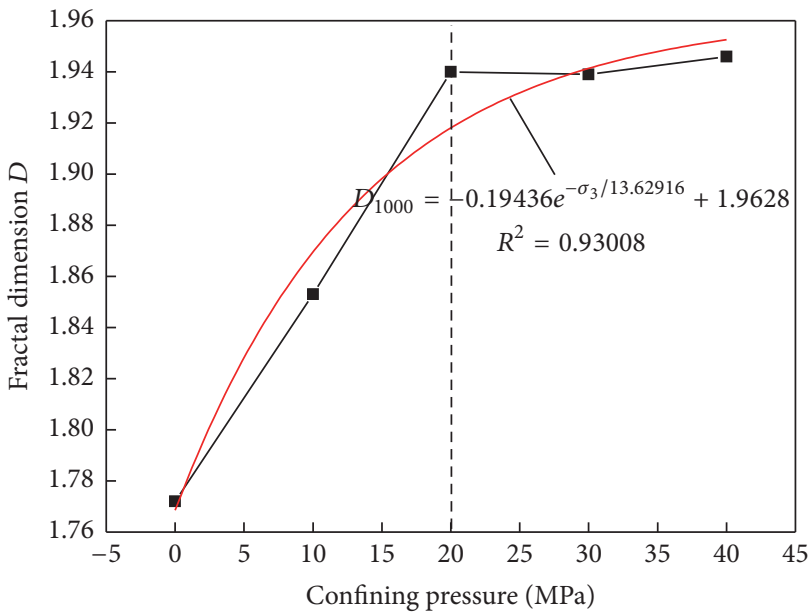

(f) $1000^{\circ} \mathrm{C}$

FIGURE 5: Relationship between fractal dimension and confining pressure. 


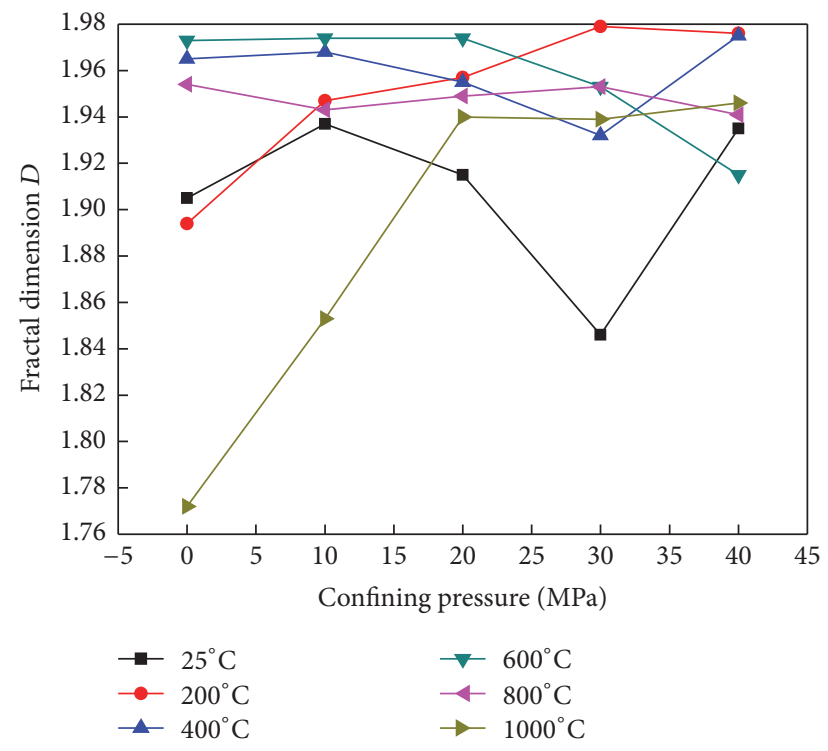

FIGURE 6: Relationship between fractal dimension and confining pressure under temperature at all levels.

It can also be seen by the overall figure that the influence of confining pressure on FD is weakened in $400 \sim 800^{\circ} \mathrm{C}$; FD is mainly controlled by temperature in this section.

\section{Discussion}

Through this research, when confining pressure is in the range of $0 \sim 30 \mathrm{MPa}, \mathrm{FD}$ first increases and then decreases with the rise of temperature, reaching the maximum value at $600^{\circ} \mathrm{C}$ (except $30 \mathrm{MPa}$ ); it can be considered that $600^{\circ} \mathrm{C}$ is the critical temperature of granite. The main reasons are as follows. When temperature is below $600^{\circ} \mathrm{C}$, the pore water, interlayer water, and structure water of rock is gradually evaporated; some of the original crack is closured due to the thermal expansion induced by the increase of temperature, and the friction between molecules is enhanced; all of these factors lead to the enhancement of mechanical properties of rock, resulting in more complex cracks when the rock is destroyed, so FD increases with the rise of temperature below $600^{\circ} \mathrm{C}$. When temperature exceeds $600^{\circ} \mathrm{C}$, thermal stress generated by temperature leads to thermal cracking of rock. By diffraction information of granite [26,27], quartz as the main component of granite occurs by reversible reaction of $\alpha$ quartz to $\beta$ quartz at $573^{\circ} \mathrm{C}$; differential thermal curve of feldspar appears as endothermic valley at $700 \sim 900^{\circ} \mathrm{C}$; structure changes from crystalline to amorphous phase; crystal lattice of mica is destroyed at $997^{\circ} \mathrm{C}$, leading to escapement of hydroxyl and formation of sodium feldspar; these chemical reactions lead to continuous cracking, expansion, and integration and through cracks in the rock, the interaction of these factors leads to the decrease of FD of rock fracture over $600^{\circ} \mathrm{C}$.

The study found that when discussing the influence of temperature on FD under various confining pressure, $30 \mathrm{MPa}$ is a watershed. With the increase of confining pressure, rock occurs from brittle to plastic transition. From this research it can be initially considered that $30 \mathrm{MPa}$ is the critical confining pressure of granite from brittle to plastic transition; this result is consistent with Huang et al. [13]. In their study, it is found that when confining pressure is over $30 \mathrm{MPa}$, large plastic flow in the vicinity of peak point is found.

At the same time, this study also obtained that FD of rock fracture has fluctuation with the increase of confining pressure at $25^{\circ} \mathrm{C}$ (normal temperature), which can be divided into three stages, reaching the minimum value at $30 \mathrm{MPa}$. This result is inconsistent with previous research results, such as Chen et al. [12] and Yang et al. [14], where their research got that $\mathrm{FD}$ of rock crack decreased with the increase of confining pressure at $25^{\circ} \mathrm{C}$; Ni et al. [11] and Huang et al. [13] found that $\mathrm{FD}$ increased with the rise of confining pressure. Inconsistent research results may be related to the kind of rock specimen, loading method, calculation of FD, rock brittle to plastic transition, micro fracture mechanism, and so on; the specific reason is yet to be further studied.

\section{Conclusions}

(1) In the test range of temperature $\left(25 \sim 1000^{\circ} \mathrm{C}\right)$ and confining pressure $(0 \sim 40 \mathrm{MPa})$, the variation of $\mathrm{FD}$ of SEM images with temperature is closely related to confining pressure; it can be generally divided into two categories. In the first category, when confining pressure is in $0 \sim 30 \mathrm{MPa}, \mathrm{FD}$ increases with cubic polynomial fitting curve with temperature, but correlation coefficient of fitting curve decreases with the rise of confining pressure; there is no better fitting curve at $30 \mathrm{MPa}$. In the second category, when confining pressure is in $30 \sim 40 \mathrm{MPa}$, FD has volatility with the change of temperature; the change law of $400 \sim 1000^{\circ} \mathrm{C}$ is just opposite to the same range of temperature of $0 \sim 30 \mathrm{MP}$; confining pressure plays a leading role in this case.

(2) In the test range, the variation of FD with confining pressure is closely related to temperature, which can be divided into three categories. In the first category, $\mathrm{FD}$ has volatility with the change of confining pressure at $25^{\circ} \mathrm{C}, 400^{\circ} \mathrm{C}$, and $800^{\circ} \mathrm{C}$. In the second category, it increases exponentially with confining pressure at $200^{\circ} \mathrm{C}$ and $1000^{\circ} \mathrm{C}$. In the third category, it decreases exponentially with confining pressure at $600^{\circ} \mathrm{C}$.

(3) Through this study, it is obtained that $600^{\circ} \mathrm{C}$ and $30 \mathrm{MPa}$ are the critical temperature and confining pressure of granite. When temperature exceeds $600^{\circ} \mathrm{C}$ and confining pressure exceeds $30 \mathrm{MPa}$, rock occurs from brittle to ductile transition; the influence of temperature on $\mathrm{FD}$ is weakened by the increase of confining pressure.

It is worth pointing out that this paper considers triaxial compression test of rock after high temperature cooling, while the mechanical properties of rock differ from real time 
high temperature and high temperature cooling. The variation of FD of rock fracture with the change of temperature and confining pressure under real time high temperature also has a good value of scientific research; this part will be further studied through the follow-up experiment.

\section{Abbreviations}

SEM: Scanning Electron Microscopy

FD: Fractal dimension.

\section{Competing Interests}

The authors declare that they have no competing interests.

\section{Acknowledgments}

This work had been financially supported by the National Natural Science Foundation of China (no.11202108, 51604260), the Opening Fund of State Key Laboratory for Geomechanics and Deep Underground Engineering of China University of Mining and Technology (no. SKLGDUEK1204), the Natural Science Foundation of Jiangsu Province of China (no. BK20160416), the China Postdoctoral Science Foundation (no. 2016T90519), and the Jiangsu Postdoctoral Sustentation Fund of China (no. 1501085B).

\section{References}

[1] B. B. Mandelbrot, The Fractal Geometry of Nature, W. H. Freeman, New York, NY, USA, 1982.

[2] H. P. Xie and Z. D. Chen, "Fractal Geometry and fracture of rock," Acta Mechanica Sinica, vol. 20, no. 3, pp. 264-271, 1988.

[3] H. P. Xie, "Fractal geometry and its application in the rock mechanics," Chinese Journal of Geotechnical Engineering, vol. 14, no. 1, pp. 14-24, 1992.

[4] Z. R. Niu and X. J. Shi, "Statistical theory of rock fractal fracture," Acta Geophysica Sinica, vol. 35, no. 5, pp. 594-603, 1992.

[5] F. Gao and P. Zhao, "Rock crushing degree of fractal measurement," Mechanics in Engineering, vol. 16, no. 2, pp. 16-17, 1994.

[6] F. Gao, H. P. Xie, and J. B. Wu, "Fractal analysis of rock damage and breakage correlation," Chinese Journal of Rock Mechanics and Engineering, vol. 18, no. 5, pp. 503-506, 1999.

[7] H. P. Xie, F. Gao, H. W. Zhou, and J. P. Zuo, "Fractal fracture and fragmentation in rocks," Journal of Disaster Prevention and Mitigation Engineering, vol. 23, no. 4, p. 1, 2003.

[8] R.-D. Peng, H.-P. Xie, and Y. Ju, "Computation method of fractal dimension for 2-D digital image," Journal of China University of Mining \& Technology, vol. 33, no. 1, pp. 19-24, 2004.

[9] R. D. Peng, Y. C. Yang, Y. Ju, L. T. Mao, and Y. M. Yang, "Calculation of fractal dimension of rock pore space based on gray scale CT image," Chinese Science Bulletin, vol. 56, no. 26, pp. 2256-2266, 2011.

[10] J. Zuo, W. Y. Xu, H. L. Wang, and Q. X. Meng, "Fractal analysis of SEM image for rocks," Journal of China Three Gorges University (Natural Sciences), vol. 36, no. 2, pp. 72-76, 2014.

[11] Y. S. Ni, Z. B. Kuang, and Y. Q. Yang, "Fractal study of the fracture surface of granite caused by triaxial compression,"
Chinese Journal of Rock Mechanics and Engineering, vol. 11, no. 3, pp. 295-303, 1992.

[12] Z. H. Chen, L. G. Tham, and M. R. Yeung, "Numerical simulation of damage and failure of rocks under different confining pressures," Chinese Journal of Geotechnical Engineering, vol. 23, no. 5, pp. 576-580, 2001.

[13] D. Huang, Q. Tan, and R. Huang, "Fractal characteristics of fragmentation and correlation with energy of marble under unloading with high confining pressure," Chinese Journal of Rock Mechanics and Engineering, vol. 31, no. 7, pp. 1379-1389, 2012.

[14] Y.-M. Yang, Y. Ju, and L.-T. Mao, "Growth distribution laws and characterization methods of cracks of compact sandstone subjected to triaxial stress," Chinese Journal of Geotechnical Engineering, vol. 36, no. 5, pp. 864-872, 2014.

[15] X.-L. Xu, F. Gao, X.-M. Shen, and C.-H. Jin, "Research on mechanical characteristics and micropore structure of granite under high-temperature," Rock and Soil Mechanics, vol. 31, no. 6, pp. 1752-1758, 2010.

[16] P. Cao, G. G. Ning, X. Fan, H. H. Mei, and X. J. Huang, "Influence of water-rock interaction on morphological characteristic of rock joint surface at different temperatures," Journal of Central South University (Science and Technology), vol. 44, no. 4, pp. 1510-1516, 2013.

[17] H.-J. Su, H.-W. Jing, and H.-H. Zhao, "Experimental investigation on loading rate effect of sandstone after high temperature under uniaxial compression," Chinese Journal of Geotechnical Engineering, vol. 36, no. 6, pp. 1064-1071, 2014.

[18] R. Zhang, S. Y. Zhu, Q. Sun, and F. Q. Wu, "Fractal characteristics of limestone after high temperature under uniaxial compression," China Earthquake Engineering Journal, vol. 37, no. 2, pp. 541-545, 2015.

[19] Z. Z. Zhang, X. L. Xu, Q. P. Sun, and Y. Dong, "Effect of thermal treatment on fractals in acoustic emission of rock material," Advances in Materials Science and Engineering, vol. 2016, Article ID 6309856, 9 pages, 2016.

[20] Z. Z. Zhang, "Fractal dimension of fracture surface in rock material after high temperature," Advances in Materials Science and Engineering, vol. 2015, Article ID 468370, 6 pages, 2015.

[21] S. Z. Wang, "High-temperature/high-pressure rock mechanics: history, state-of-art and prospect," Progress in Geophysics, vol. 10, no. 4, pp. 1-31, 1995.

[22] N. A. Al-Shayea, K. Khan, and S. N. Abduljauwad, "Effects of confining pressure and temperature on mixed-mode (I-II) fracture toughness of a limestone rock," International Journal of Rock Mechanics and Mining Sciences, vol. 37, no. 4, pp. 629-643, 2000.

[23] L. Jing and X. Feng, "Main rock mechanics issues in geological disposal of radioactive wastes," Chinese Journal of Rock Mechanics and Engineering, vol. 25, no. 4, pp. 833-841, 2006.

[24] Z.-Z. Zhang, F. Gao, and X.-J. Shang, "Rock burst proneness prediction by acoustic emission test during rock deformation," Journal of Central South University, vol. 21, no. 1, pp. 373-380, 2014.

[25] X.-L. Xu, F. Gao, and Z.-Z. Zhang, "Influence of confining pressure on deformation and strength properties of granite after high temperatures," Chinese Journal of Geotechnical Engineering, vol. 36, no. 12, pp. 2246-2252, 2014.

[26] G. X. Chen and Y. M. Zhang, Mineral Thermal Analysis Spectrum Manual of Powder Diffraction Analysis of Phase Change, Sichuan Science and Technology Press, Chengdu, China, 1989. 
[27] X.-L. Xu, F. Gao, Z.-Z. Zhang, and C.-H. Zhang, "Energy and structural effects of granite after high temperature," Chinese Journal of Geotechnical Engineering, vol. 36, no. 5, pp. 961-968, 2014. 

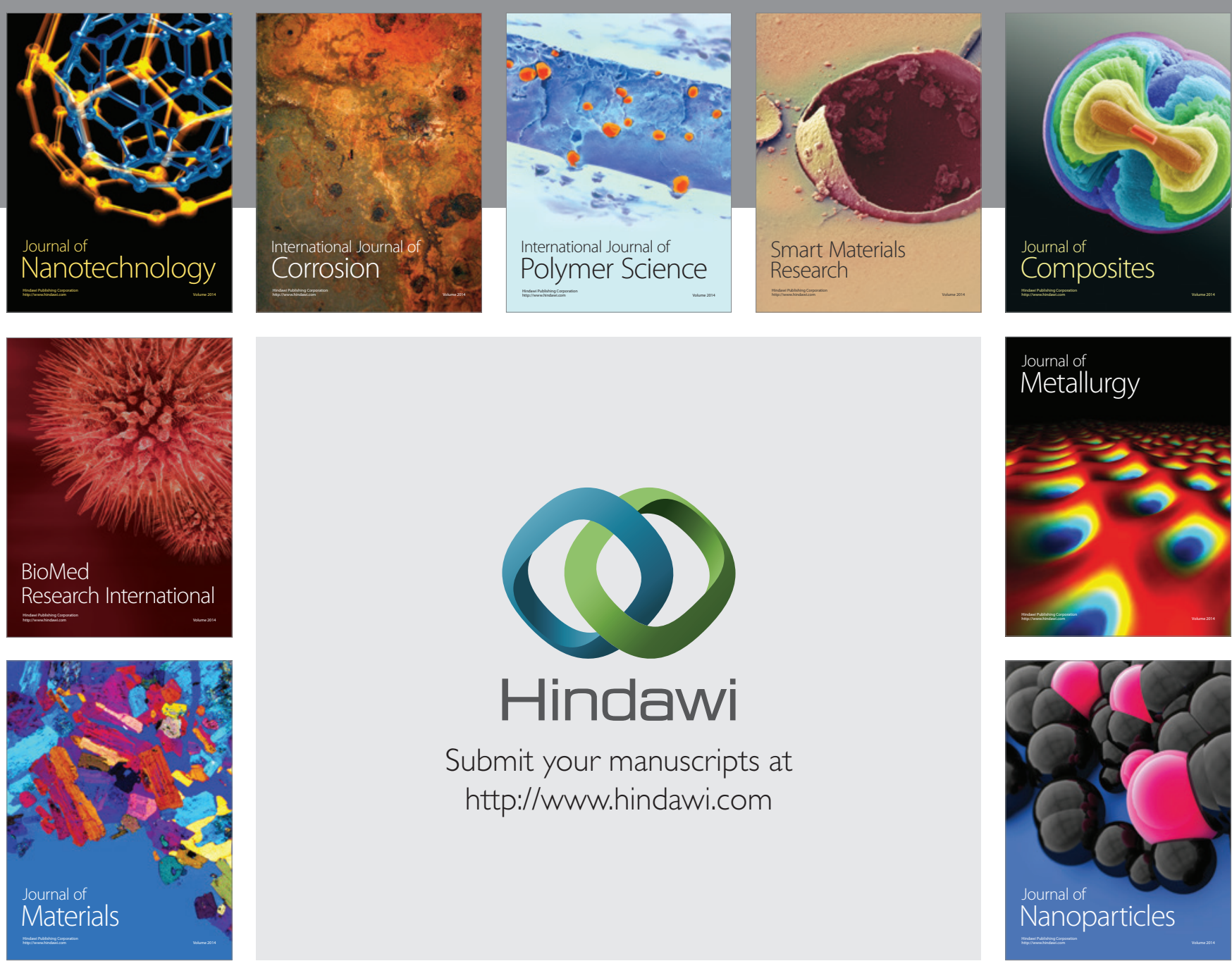

\section{Hindawi}

Submit your manuscripts at

http://www.hindawi.com

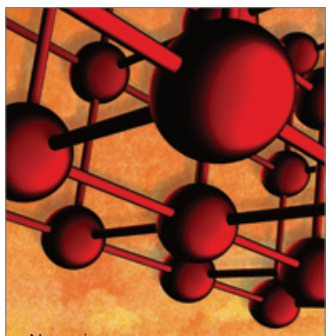

Materials Science and Engineering
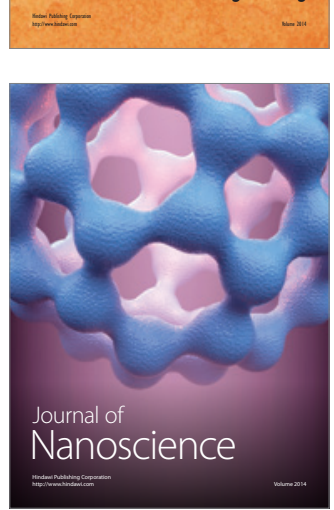
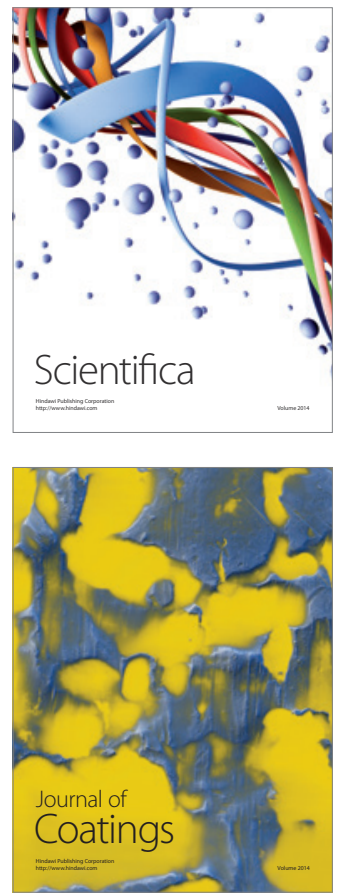
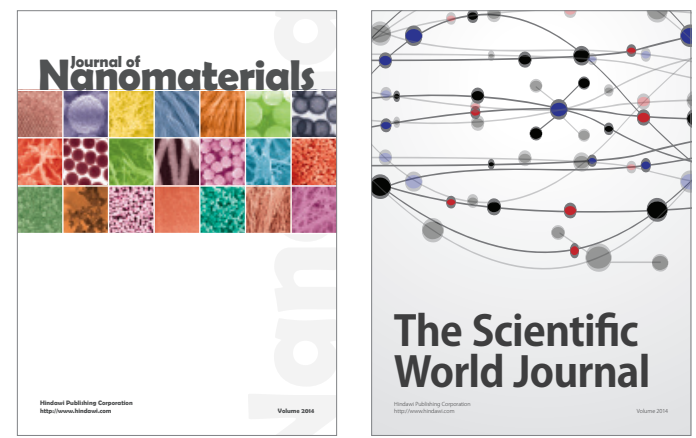

The Scientific World Journal
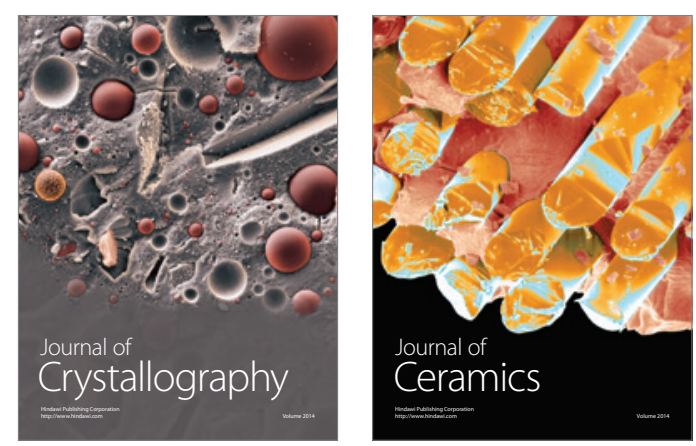
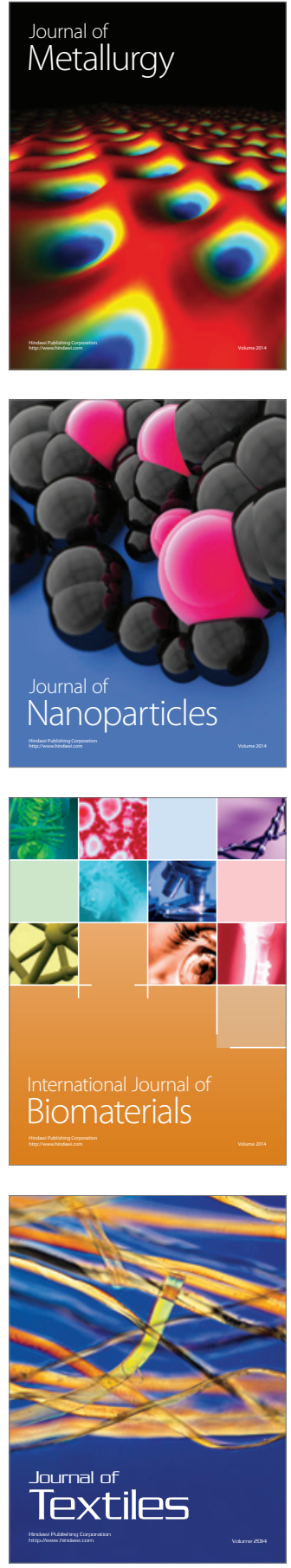